\title{
Relative DNA content in diploid, polyploid, and multiploid species of Paspalum (Poaceae) with relation to reproductive mode and taxonomy
}

\author{
Florencia Galdeano $^{1}$ M. H. Urbani ${ }^{1}$ M. E. Sartor ${ }^{1}$ A. I. Honfi ${ }^{2}$ - F. Espinoza ${ }^{1}$ \\ C. L. Quarin ${ }^{1}$
}

Received: 12 August 2015 / Accepted: 21 January 2016 / Published online: 10 March 2016

(C) The Botanical Society of Japan and Springer Japan 2016

\begin{abstract}
It is generally accepted that polyploids have downsized basic genomes rather than additive values with respect to their related diploids. Changes in genome size have been reported in correlation with several biological characteristics. About $75 \%$ of around 350 species recognized for Paspalum (Poaceae) are polyploid and most polyploids are apomictic. Multiploid species are common with most of them bearing sexual diploid and apomictic tetraploid or other ploidy levels. DNA content in the embryo and the endosperm was measured by flow cytometry in a seedby-seed analysis of 47 species including 77 different entities. The relative DNA content of the embryo informed the genome size of the accession while the embryo:endosperm ratio of DNA content revealed its reproductive mode. The genome sizes (2C-value) varied from 0.5 to $6.5 \mathrm{pg}$ and for 29 species were measured for the first time. Flow cytometry provided new information on the reproductive mode for 12 species and one botanical variety and supplied new data for 10 species concerning cytotypes reported for the first time. There was no significant difference between the mean basic genome sizes (1Cx-values) of 32 sexual and 45 apomictic entities. Seventeen entities were diploid and 60 were polyploids with different degrees. There were no clear patterns of changes in $1 \mathrm{Cx}$-values due to polyploidy or reproductive systems, and the existing variations are in concordance with subgeneric taxonomical grouping.
\end{abstract}

Florencia Galdeano

floppy@agr.unne.edu.ar; galdeanoflorencia@gmail.com

1 Instituto de Botánica del Nordeste, CONICET-UNNE, Facultad de Ciencias Agrarias, FCA-UNNE, J.B. Cabral 2131, 3400 Corrientes, Argentina

2 Instituto de Biología Subtropical, CONICET-UNaM, Facultad de Ciencias Exactas, Químicas y Naturales, UNaM, Rivadavia 2370, 3300 Posadas, Misiones, Argentina
Keywords 1Cx-value $\cdot 2 \mathrm{C}$-value $\cdot$ Flow cytometry Relative DNA content

\section{Introduction}

The use of flow cytometry to estimate the DNA (deoxyribonucleic acid) content in plant nuclei has facilitated analysis in relation to fundamental aspects of plant biology. Genome size is an expression to specify the DNA content of the whole chromosome complement characteristic of any given individual in terms of $1 C$-value (Swift 1950). In order to clarify the term, Greilhuber et al. (2005) suggested that when the genome size is based on the whole unreplicated reduced chromosome complement, the abbreviated term is 1C-value, equal to half of the unreplicated non-reduced (zygotic diplophasic) complement, which has a $2 \mathrm{C}$-value. The $1 \mathrm{Cx}$-value is applied when genome size is referred to the monoploid chromosome set and represents the basic genome size. Correlations between genome size and specific biological traits have been documented repeatedly in higher plants. For example, annuals usually have lower genome size than related perennials, especially when annual life history is associated with selfing, and higher genome size is positively associated with high elevation habitat in the genus Veronica (Albach and Greilhuber, 2004). Significant differences have been found in $1 \mathrm{Cx}$-values between diploid and triploid genotypes and between triploids and tetraploids, indicating downsizing of genomes in polyploids of Hieracium, a genus in which the genome size is strongly correlated with major phylogenetic groups but is not correlated with altitude, latitude and other ecological characters (Chrtek et al. 2009). Considering the tendency toward an increase in genome size during the evolution of angiosperm, Bennetzen and Kel$\log$ (1997) considered that the angiosperm genomes have 
a "one-way ticket to obesity". However, Enke et al. (2011) demonstrated that there is a shrinking trend toward genome contraction within 30 diploid species of Crepis. Correlation of DNA content, phylogenetic characteristics and reproductive mode has been documented in the genus Hypericum (Matzk et al. 2003). The apomictic species of the modern section Hypericum increases the DNA content solely by polyploidy, while the apomicts of the earlier evolving section Ascyreia have significantly larger genomes than all other species due to polyploidization and also by higher DNA content per chromosome.

With approximately $330-350$ species, Paspalum is one of largest genus of the Panicoid grass subfamily (Rua et al. 2010; Zuloaga and Morrone 2005). The great majority of its species are native of the Americas, distributed throughout the tropics, subtropics and temperate regions from northern Unites States to southern Chile and southwestern Argentina, at approximately $38^{\circ}$ south latitude. A few species are native to Africa, Asia, or Oceania, and only three or four are cosmopolitan but probably of American origin (Rua et al. 2010). Several species of Paspalum are the main constituents of natural extensive pasturelands in South America, especially in Brazil, Paraguay, Argentina and Uruguay. Some species have been brought into cultivation due to their recognized forage quality. Because a great proportion of polyploid Paspalum species are apomictic (asexual reproduction by seed) the main breeding approach to obtain cultivated forage species was the simple process of collection, evaluation, and selection of those biotypes with better agronomic qualities (Blount and Acuña 2009). With this breeding approach, apomictic polyploids such as $P$. dilatatum (dallisgrass), $P$. plicatulum, $P$. guenoarum, $P$. nicorae, $P$. atratum and $P$. notatum (bahiagrass) have been used in southern Unites States, Australia, New Zealand, Japan, Uruguay, Argentina, Brazil, Paraguay, Zimbabwe, and Thailand to start breeding a promising species for forage purpose, or to develop a new cultivar (Blount and Acuña 2009; Evers and Burson 2004). The most important cultivated Paspalum species is Pensacola, P. notatum var. saurae, which belong to the sexual diploid $(2 \mathrm{n}=20)$ cytotype of bahiagrass. It is one of the most popular perennial pasture grasses in Florida and the southern part of the Gulf States. Its persistence, ability to grow on poor soils, excellent seeding habits, and ease of establishment are responsible for much of its popularity (Burton and Forbes 1970). It was accidentally introduced to Unites States probably before 1926 (Burton 1967) from its native distribution, a small area in central-eastern Argentina (Daurelio et al. 2004). There are actually several millions of hectares of naturalized or cultivated Pensacola bahiagrass or genetically improved cultivars in the United States and, in addition, it was sold and cultivated for forage or turf purposes in many temperate and warm regions around the world.
Two main biological characteristics are well represented in Paspalum: apomixis is a common feature in many species of the genus and multiploidy occurs in a large proportion of it species. According to Savidan (2007), over 500 species have been reported to reproduce apomictically in about 40 higher plant families, while in the genus Paspalum at least 45 species are apomictic (Ortiz et al. 2013), which represent $9 \%$ of the total number of apomictic plant species known at present. Multiploids, species with different ploidy levels or in other words different cytotypes for the same species, constitute $40 \%$ of the known polyploids. The current cytological data indicate that about $75 \%$ of Paspalum species are polyploid or multiploid. These species frequently have a diploid cytotype and one or more polyploid cytotypes, usually a tetraploid. Diploid cytotypes reproduce sexually, while polyploid counterparts reproduce by apomixis (Ortiz et al. 2013). Multivalent chromosome associations at meiosis are the rule in polyploid cytotypes of multiploid species (reviewed in Quarin 1992). Thus, cytological results suggest that polyploid cytotypes, particularly tetraploids and triploids, originated by autoploidy or segmental alloploidy in P. notatum (Forbes and Burton 1961), P. simplex (Pupilli et al. 1997) and P. rufum (Quarin et al. 1998). Moreover tetrasomic inheritance was observed through molecular markers analyses in the $4 \times$ cytotypes of the multiploids species of P. simplex (Pupilli et al. 1997) and P. notatum (Stein et al. 2004). Therefore, these previous results have strongly suggested that the existence of multiploid species is a biological characteristic feature of the genus Paspalum, and sustained that the polyploid cytotypes likely originated by autoploidy from diploid counterparts, though a segmental alloploid origin would not be discarded in some cases.

The genome size has been established for 43 of the approximately 350 species of the genus Paspalum (Jarret et al. 1995; Vaio et al. 2007). The amount varied roughly fourfold (1.02-3.86 pg/2C nucleus) and was considered a useful descriptor for characterization of plant genetic resources. Nevertheless, a question arises as to whether genome size and some biological traits are correlated in the genus Paspalum, especially the reproductive mode, the ploidy level, and the current concepts on infrageneric taxonomical classification. The main task to elucidate this question is the identification of the actual reproductive pathway of individual plants in multiploid species, a condition which tends to be the rule for several taxonomic groups of the genus as new data on chromosome numbers are achieved for different accessions of the same species.

Fortunately, the development of flow cytometric seed screen (FCSS) facilitates the simultaneous analysis of the relative DNA content and the mode of reproduction for large sample numbers. By using dry seeds from a target entity it is possible to know the relative DNA content of the 
embryos and to assess the reproductive mode by the ratio of DNA content between the embryo and the endosperm of the seeds (Matzk et al. 2000). Thus, in a FCSS the DNA content of the embryo informs the $2 \mathrm{C}$-value of a given individual and the embryo:endosperm DNA content ratio reveals its reproductive mode. The method is especially suitable to the analysis in Paspalum since apomixis in the vast majority of Paspalum species belongs to the aposporous type. Normaly, the sexual plants develop cytologically reduced megagametophytes with an egg apparatus (egg cell and two synergids), a large bi-nucleated central cell, and many antipodals. Thus, after double fertilization, a seed is formed with a $2 n$ embryo and a $3 n$ endosperm, or respectively $2 \mathrm{C}$ and $3 \mathrm{C}$ in terms of DNA content. In aposporous embryo sacs of the apomictic plants, the nuclear constitution may be very variable though usually there is one unreduced egg cell ( $2 n)$, accompanied or not by one or two synergids, and a large central cell containing two unreduced polar nuclei, while antipodals are usually absent. Following parthenogenesis of the unreduced egg cell (2n) and fertilization of the two unreduced polar nuclei ( $2 \mathrm{n}$ each) by a reduced sperm cell (n) (pseudogamy), a seed is formed bearing a $2 n$ embryo $(2 C)$ and a $5 n$ endosperm (5C). The FCSS analysis provides the $2 \mathrm{C}$-value of the embryo and simultaneously the DNA content of the endosperm. The $2: 3$ or $2: 5$ embryo:endosperm ratios indicate the sexual or the apomictic (apospory + parthenogenesis + pseudogamy) origin of the seed, respectively (Matzk et al. 2000; Ortiz et al. 2013). However, occasional deviations from the normal sexual or apomictic pathways may occur and should be considered. For example, occasional double fertilization may occur in aposporous embryo sacs (instead of parthenogenesis) and in that case a seed with a 3:5 embryo:endosperm ratio is formed.

We have tested in a large sample of Paspalum species whether the genome size (1Cx-value) is correlated to the reproductive mode (sexual or apomictic), to different ploidy levels, and to the current infrageneric taxonomic grouping of the species according to morphological characteristics. Simultaneously, we have determined the reproduction mode for all these species through the specific ratio of embryo:endosperm DNA contents in their seeds. In most cases the results obtained through flow cytometry were compared with previous determinations by means of embryological analyses, and in the remaining species the reproduction mode was established for the first time.

\section{Materials and methods}

The mode of reproduction and the relative DNA content were analysed for 47 species, i.e. 47 botanical taxa at the species rank. In Paspalum, below the species ranking it is possible to separate different categories: from the officially recognized subspecies or botanical varieties to different cytotypes (organisms that belong to the same species but have different ploidy levels) or very special biotypes (e.g. experimental hybrids, colchicine-induced polyploids, or botanical collections included in a given species but differing in some morphological or cytological characteristics from the species type). Consequently, a total of 77 different entities were examined, ranking from species (47), subspecies (1), botanical varieties (2), and different intraspecific cytotypes or biotypes (27). In most entities only one individual plant was analysed. Exceptionally, more than one accession (individuals of the same species collected at different localities) was considered. Thus, a total of 91 individuals were examined. The 47 species examined in this study are currently assigned to three different subgenera (Zuloaga and Morrone 2005): Anachyris for which three species were measured, including 7 entities; Ceresia with one species analysed; and subgenus Paspalum with 43 species, 39 of which are classified among 16 informal taxonomic categories (groups), while P. durifolium, P. equitans, P. redondense, and $P$. rufum have not been assigned to any group. The use of "group" as informal secondary taxonomic category between genus and species ranks was established by Chase (1929) and widely used in grass taxonomic literature since then (see the Article 4 of The International Code of Nomenclature for algae, fungi, and plants-Melbourne Code-http://www.iapt-taxon.org/nomen/main. php for officially accepted secondary ranks in descending sequence between genus and species, and below species rank).

Seed samples were originated from living collections in greenhouses or in the experimental Paspalum nursery on campus of the Faculty of Agricultural Sciences, Corrientes, Argentina (FCA UNNE). In most cases the name of the accession was composed of letter(s) and numbers: letters stand for some of the collector's name initials and the numbers for the herbarium voucher number. Most herbarium vouchers are deposited in the CTES herbarium. The main exceptions are those accessions identified with a number preceded by the letters $\mathrm{V}$ or TK, which have been collected by J.F.M. Valls or T. Killeen and the vouchers are deposited in the CEN or the US herbaria, respectively (for herbarium codes see: http://sweetgum.nybg.org/ih/). Exceptionally, the name of the accession reflects just the collection site.

The ploidy levels and the specific chromosome numbers were already known for several accessions because they had been previously reported in different publications of the Paspalum research team at FCA-UNNE. Chromosome numbers for the remaining accessions were determined through chromosome counts in root tips according to the procedures described in Norrmann et al. (1994). 
For the flow cytometry seed screen (FCSS), a Partec Flow Cytometer CA and a Partec PA II were used at IPK, Gatersleben, Germany, and at Botanical Institute of Northeast, Corrientes, Argentina, respectively. Preparation, measurement and interpretations of the histograms were made as described by Matzk et al. (2000). The nuclei were stained with DAPI (4', 6-diamidino-2-phenylindole) using the CyStain UV Precise P kit (05-5002) from Partec. The measurements of relative fluorescence intensity of stained nuclei were performed on a linear scale, with at least 3000 nuclei per sample and CV $\leq 8 \%$ (Fig. 1). In most cases 15-25 seeds were analysed for each entity in order to assess the reproductive mode and to establish the relative DNA content of each target entity. The protocol of Matzk et al. (2000) is suitable either for bulked or for single seed analysis. We used the seed-by-seed analysis, a procedure that reveals more clear evidence for facultative apomixis than the bulked analysis. Facultative apomicts form seeds not only through apomictic pathways (apospory or diplospory, parthenogenesis, and usually pseudogamy) but also by sexual means. In Germany, the relative DNA content was registered by DAPI measurement, using Hypericum maculatum subsp. maculatum as internal standard (relative $1 \mathrm{C}$-value $=2.0 \mathrm{pg}$; Matzk et al. 2001 and 2003). In Argentina diploid Paspalum notatum var. saurae (relative $1 \mathrm{C}$-value $=1.2 \mathrm{pg}$ in comparison to Hypericum maculatum subsp. maculatum) was used as internal standard.

In the FCSS we follow the short forms used by Matzk et al. (2000) for the 1C-values of the embryo and the endosperm nuclei of the tested seed samples. Thus, the formula $2 \mathrm{C}+(3 \mathrm{C})$ stands for a seed developed from an ovule bearing a reduced embryo sac through a double fertilization process by reduced sperms. An apomictically formed seed shows a $2 \mathrm{C}+(5 \mathrm{C})$ formula corresponding to parthenogenetic embryo development from the unreduced egg cell and the pseudogamous formation of the endosperm (syngamy of two unreduced polar nuclei of the aposporous embryo sac and one reduced sperm). Though sexual species developing seeds with $2 \mathrm{C}+(3 \mathrm{C})$ histogram peaks, or apomictic species showing $2 \mathrm{C}+(5 \mathrm{C})$ represent the two most common combinations in the embryo:endosperm ratios of DNA content in Paspalum species, some exceptions have to be considered. The array of possible combinations in the DNA content of embryo and endosperm nuclei in monocots and dicots with respect to reproductive events are summarized in Matzk et al. (2000). According to previous research (e.g. Sartor et al. 2011), and our current expertise in cytology, embryology and flow cytometry to deal with reproductive mode in this grass material, the main exceptions for the rule that could be found in Paspalum are: (1) Entities

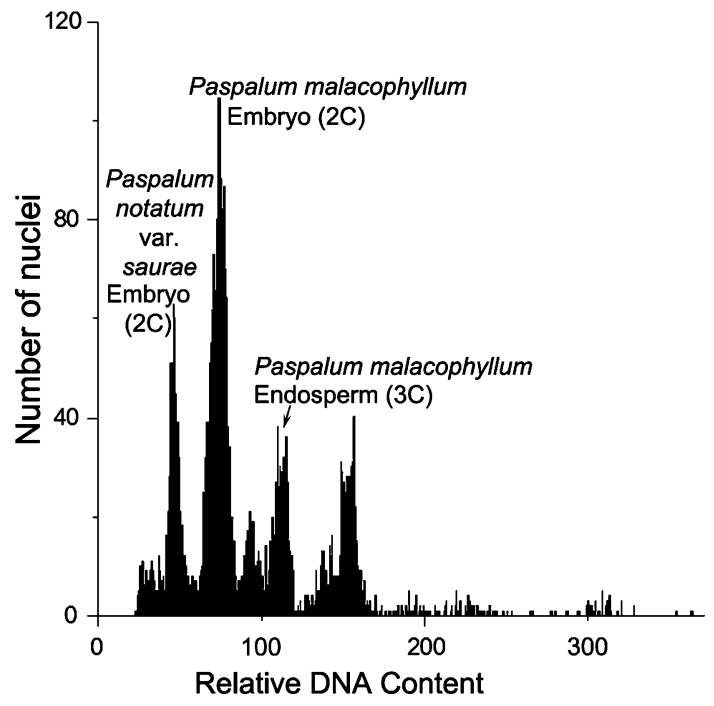

Fig. 1 Histogram illustrating the relative DNA content of $2 \mathrm{C}$ for diploid Paspalum notatum var. saurae (standard) and $(2 \mathrm{C})+(3 \mathrm{C})$ of diploid P. malacophyllum (V14855) obtained by flow cytometric analysis of DAPI stained nuclei isolated from mature seeds. The (3C) peak corresponding to endosperm of the standard is overlapped by the (2C) peak of P. malacophyllum. Other peaks correspond to G2 of each respective embryo

for which most seeds show $2 \mathrm{C}+(5 \mathrm{C})$ contents, though some seeds with $2 \mathrm{C}+(3 \mathrm{C})$ peaks are also observed. These entities are interpreted as facultative apomictic (fap). (2) Apomictic entities showing mainly $2 \mathrm{C}+(5 \mathrm{C})$ peaks, but with some occasional $3 \mathrm{C}+(5 \mathrm{C})$ histograms, which imply double fertilization of an aposporous embryo sac, forming occasional $\mathrm{B}_{\mathrm{III}}(2 n+n)$ embryos. (3) Entities forming histograms with $2 \mathrm{C}+(6 \mathrm{C})$ peaks or occasional $4 \mathrm{C}+(6 \mathrm{C})$ or even $2 \mathrm{C}+(5 \mathrm{C}$ to $6 \mathrm{C})$. The interpretation of a $6 \mathrm{C}$ value in the endosperm is that pseudogamy has been accomplished by unreduced male gametes (umg), while the variation in the endosperm DNA content from more or less $5 \mathrm{C}$ to about $6 \mathrm{C}(\sim 5 \mathrm{C})$ is attributed to chromosomically variable male gametes (vmg) due to irregular meiotic chromosome behaviour. The occasional $4 \mathrm{C}$ value in the embryo nuclei reveals the formation of $2 n+2 n$ embryos involving both female and male unreduced gametes. (4) Variable DNA contents among embryos of some entities with odd ploidy levels may be observed when sexual pathways occur. It should be attributed to chromosomically variable female gametes (vfg) and/or vmg due to unbalanced chromosome distribution during meiotic divisions. (5) Entities showing $2 \mathrm{C}+(4 \mathrm{C})$ peaks, attributable to autonomous apomixis (aap) with parthenogenesis but not pseudogamy (autonomous endosperm development). InfoStat version 2014 was used for statistical analyses (Di Rienzo et al. 2014). 


\section{Results}

\section{Chromosome numbers and relative DNA contents}

The chromosome numbers of the 47 sampled species varied from $2 \mathrm{n}=12$ in diploid $P$. almum to $2 \mathrm{n}=80$ in octoploid P. erianthum, P. humboldtianum, P. ionanthum, and $P$. ovale. Chromosome counts in root tips were established for 56 accessions, while the chromosome numbers of the remaining 35 accessions have already been known from our previous works (Table 1). With the exception of P. almum which has a basic (monoploid) chromosome set of $\mathrm{x}=6$ all other species showed $\mathrm{x}=10$. The $2 \mathrm{C}$-values of the embryos varied from $0.5 \mathrm{pg}$ in diploid P. fimbriatum to $6.5 \mathrm{pg}$ in octoploid P. erianthum (Table 1). The relative mean DNA content per chromosome observed in species with $\mathrm{x}=10$ varied from $0.026 \mathrm{pg}$ in $P$. fimbriatum $(1 \mathrm{Cx}$-value $=0.257 \mathrm{pg})$ to $0.100 \mathrm{pg}$ in diploid cytotypes of $P$. malacophyllum and $P$. simplex $(1 \mathrm{Cx}-$ value $=1.0 \mathrm{pg}$ ); while the diploid cytotype of $P$. almum showed a mean of $0.125 \mathrm{pg}$ and the tetraploid $0.129 \mathrm{pg}$ per chromosome with $1 \mathrm{Cx}$-values of 0.750 and $0.775 \mathrm{pg}$, respectively.

Our records of genome size are new for 29 out of the 47 species that were analysed. Twenty of the 29 species are represented by only one cytotype, 5 by two cytotypes, and 4 include three ploidy levels (see Table 1).

\section{Assessment of reproductive mode through FCSS}

In general terms, absolute coincidence was observed between the mode of reproduction previously reported according embryological studies and the present analysis of relative embryo: endosperm DNA contents (Table 1). Each species, subspecies, cytotype, or strain previously classified as sexual or apomictic by embryological studies was confirmed by FCSS, though particular variations were detected mainly in the expressed degree of the apomictic character. Some taxa that had been classified as apomictic are now classified as facultative apomictic, or vice versa. This is a meaningless difference because both categories (apomictic or facultative apomictic) have the genetic constitution for apomictic reproduction in an opposite way to those taxa that were classified as sexual, independently of the method used for classification. In addition, the relative embryo:endosperm DNA contents provided new original information on the reproductive mode for 12 species and one botanical variety of Paspalum. Furthermore, the embryo:endosperm DNA content supplied new information on the reproductive mode of 10 species concerning cytotypes different from those previously reported (Table 1).

\section{Mode of reproduction and genome size}

Seventy-seven entities were analysed taking into account species, botanical varieties, biotypes, and different ploidies: 32 reproduced by sexuality and 45 by means of apomixis (obligate or facultative). The relative DNA content of the monoploid chromosome set ( $1 \mathrm{Cx}$-value) was considered rather than the $1 \mathrm{C}$-value in order to eliminate the effect of different ploidy levels. Sexuals averaged $1 \mathrm{Cx}=0.680 \mathrm{pg}$, while the mean $1 \mathrm{Cx}$-value was $0.700 \mathrm{pg}$ for apomictic entities. Thus, no significant difference was observed between the mean basic genome size of sexual and apomictic entities $(P=0.05) .1 \mathrm{CX}$-values of sexual entities varied from $0.257 \mathrm{pg}$ in diploid $P$. fimbriatum to $1 \mathrm{pg}$ in diploid cytotypes of $P$. malacophyllum and P. plicatulum. In apomicts, the $1 \mathrm{Cx}$-value ranged from $0.475 \mathrm{pg}$ in octoploid P. humboldtianum to $0.925 \mathrm{pg}$ in the tetraploid cytotype of $P$. chaseanum.

\section{DNA content and the infrageneric taxonomic grouping}

Since we have analysed a wide range of specific variation within the genus, most infrageneric grouping are represented by few species. In consequence, we took into account only the four infrageneric categories that were represented in our study with at least 7 species in order to correlate taxonomic grouping and DNA content. The selected categories and the number of entities for each one were: subgenus Anachyris (7), the group Dilatata (9), the group Notata (11), and the group Plicatula (16). The mean DNA content (1Cx-value) varied among these four infrageneric categories (Fig. 2).

\section{DNA content and ploidy levels}

The relation between basic genome size and the ploidy levels was analysed in two different ways: first, the mean $1 \mathrm{CX}$ value of all diploid entities against the mean basic genome sizes of polyploids at different ploidy levels, and then the diploid cytotype of each multiploid species against the polyploid cytotypes of the same species.

Paspalum, unlike many other genera of angiosperms, offers the possibility to address the analysis of DNA content at different conspecific ploidy levels because many species are multiploid. Eleven of the 47 species that were analysed in this study were represented by diploid as well as polyploid cytotypes (usually a tetraploid). This circumstance allowed the comparison of the intraspecific $1 \mathrm{Cx}$-values among diploids and their conspecific polyploid counterparts (Table 2). As expected, differences in $2 \mathrm{C}$ values among conspecific cytotypes showed an increase in concordance with ploidy levels. We observed no variation or 


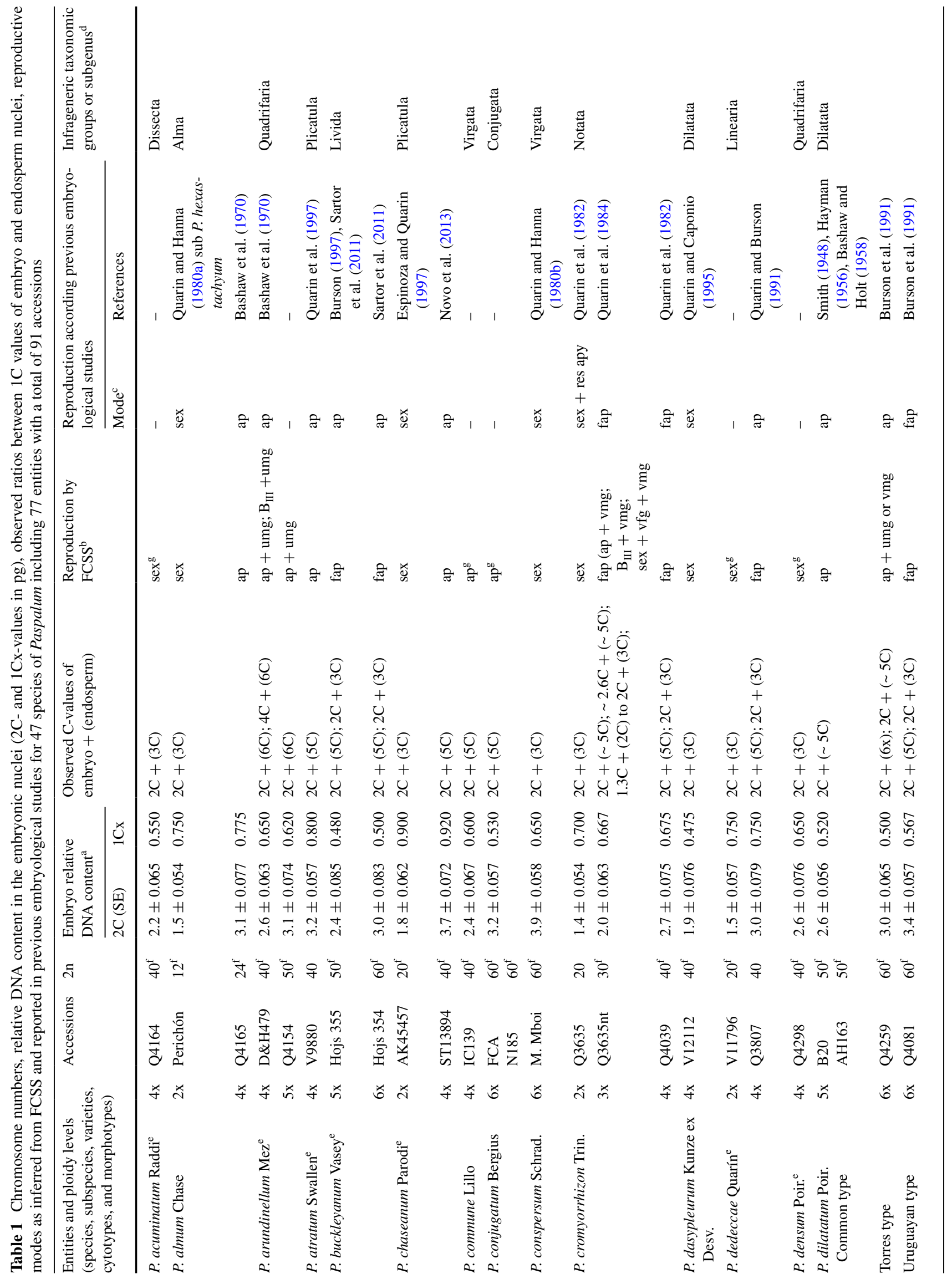




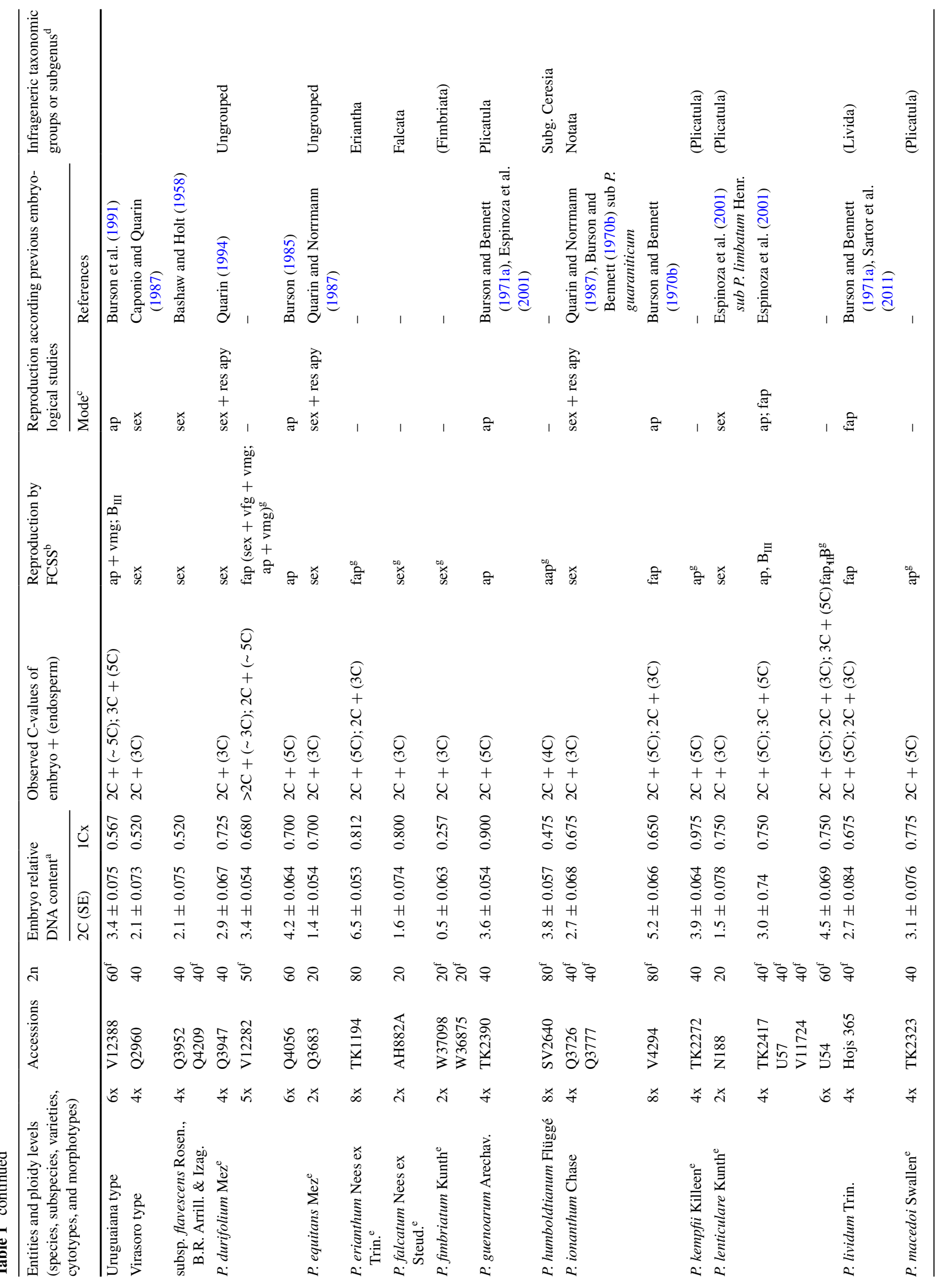




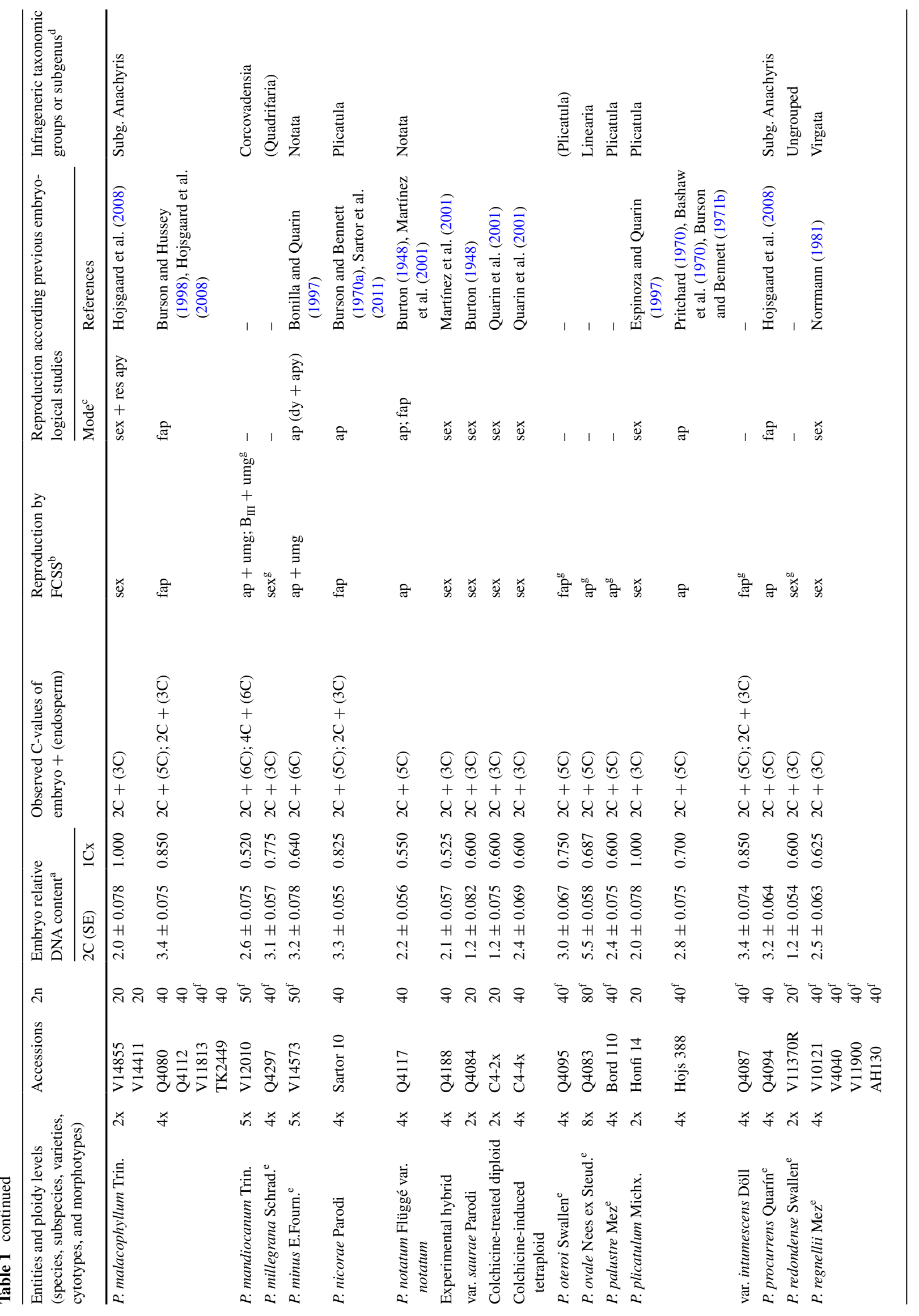




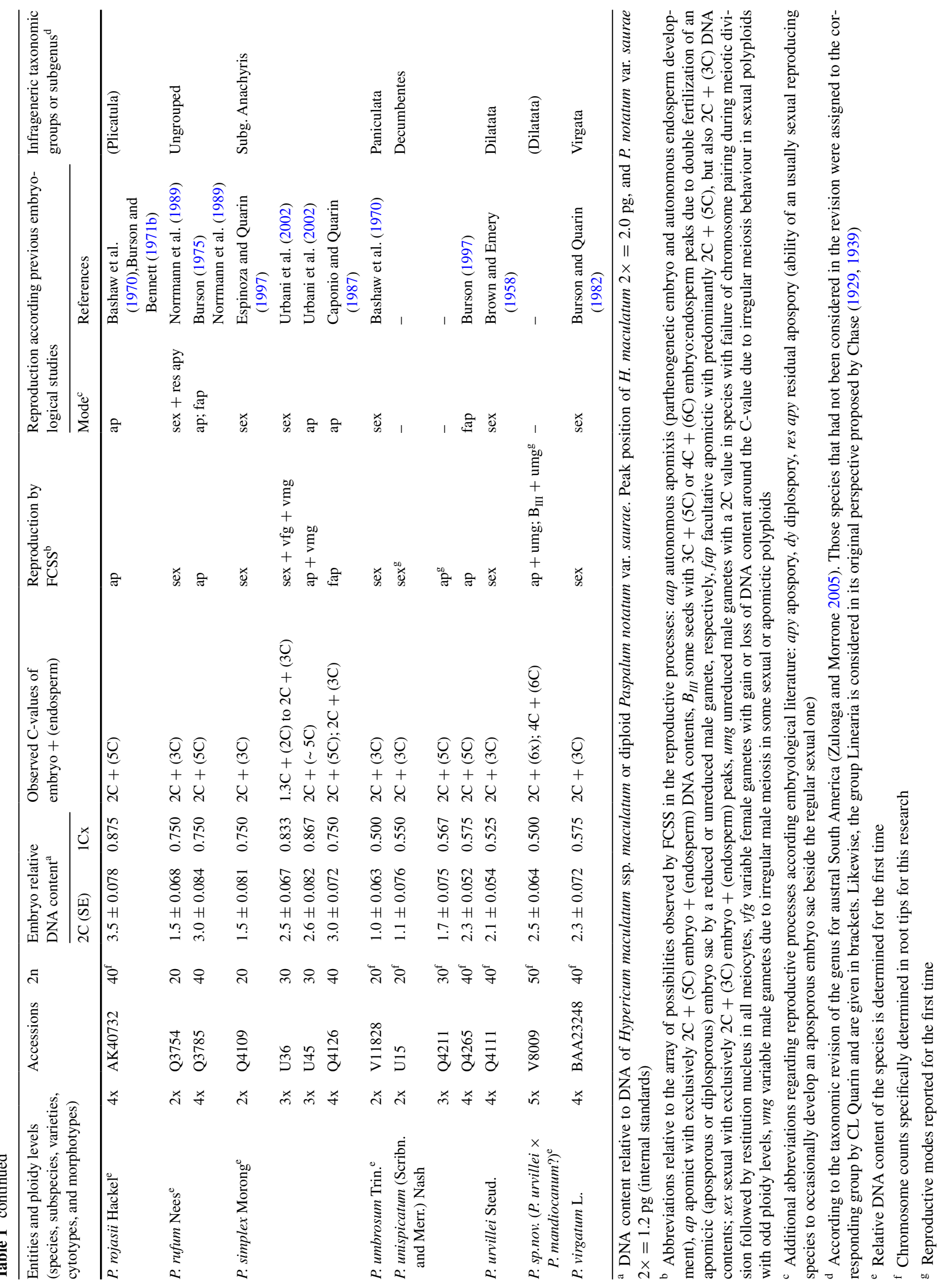




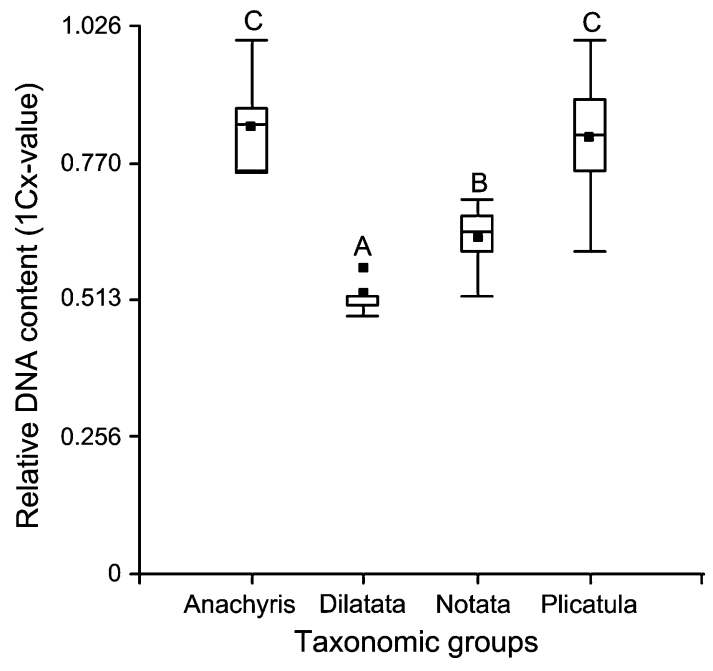

Fig. 2 Box plot with basic relative DNA Content (pg) of Paspalum species of the Subgenus Anachyris and three groups of the subgenus Paspalum. Means followed by the same letter are not significantly different. Tukey test $(P=0.05)$

not significant variation in the $1 \mathrm{Cx}$-values between conspecific cytotypes of some species; in other species there was an increase of the $1 \mathrm{Cx}$-values in polyploids, and in some cases the $1 \mathrm{Cx}$-values decreased in polyploids with respect to their diploid counterparts. Namely, the same intraspecific DNA $1 \mathrm{Cx}$-values were observed for diploid and tetraploid cytotypes of $P$. dedeccae, $P$. rufum, P.simplex, $P$. notatum (diploid accessions Q4084 and C4-2x, and tetraploid accession $\mathrm{C} 4-4 \mathrm{x}$ ); for diploid and triploid accessions of $P$. unispicatum; and for diploid, tetraploid and hexaploid cytotypes of $P$. lenticulare. In addition, the basic genome size was slightly higher or lower in polyploid cytotypes than in conspecific diploids, but not significantly different, in tetraploid P.almum $(+3.33 \%)$, tetraploid P. chaseanum $(+2.2 \%)$, tetraploid P. unispicatum $(+1.7 \%)$ and triploid and tetraploid P. cromyorrhizon ( $-4.28 \%)$. Otherwise, important increases were observed in triploids of $P$. simplex: $12 \%$ in the sexual plant U36 and $16 \%$ in apomictic plant U45, while as indicated above the tetraploid accession of this species showed the same $1 \mathrm{Cx}$-value than the diploid accession. A drastic reduction of basic genome size was observed in tetraploid P. malacophyllum (-15\%) and tetraploid P. plicatulum ( $-29 \%)$ in relation to their conspecific diploid cytotypes. A special case was $P$. notatum: natural tetraploid Q4117 had a basic genome size smaller $(-8.3 \%)$ than the natural diploid Q4084 while the colchicine-induced tetraploid $\mathrm{C} 4-4 \mathrm{x}$ had the same $1 \mathrm{Cx}$-value than the diploid $\mathrm{C} 4-2 \mathrm{x}$ from which $\mathrm{C} 4-4 \mathrm{x}$ was induced. In addition, an important genome downsizing was observed in the tetraploid Q4188 $(-13 \%)$, a particular genotype obtained through experimental means including chromosome doubling, hybridization, cycles of outcrossing and selection.
Table 2 Relative DNA contents in different cytotypes of 11 multiploid species of Paspalum

\begin{tabular}{|c|c|c|c|c|}
\hline Species & Accession & Ploidy & Cx-value (pg) & $\begin{array}{l}\text { Percentage of } \\
\text { downsized }(-) \\
\text { or upsized }(+) \\
\text { DNA content } \\
\text { with respect to } \\
2 x \text { level }\end{array}$ \\
\hline \multirow[t]{2}{*}{ P. almum } & Perichón & $2 \mathrm{x}$ & $0.750 \mathrm{a}$ & \\
\hline & Q4165 & $4 \mathrm{x}$ & $0.775 \mathrm{a}$ & +3.33 \\
\hline \multirow[t]{2}{*}{ P. chaseanum } & AK45457 & $2 x$ & $0.900 \mathrm{a}$ & \\
\hline & ST13894 & $4 \mathrm{x}$ & $0.920 \mathrm{a}$ & +2.20 \\
\hline \multirow{3}{*}{$\begin{array}{l}\text { P. cromyorrhi- } \\
\text { zon }\end{array}$} & Q3635 & $2 x$ & $0.700 \mathrm{a}$ & \\
\hline & Q3635nt & $3 x$ & $0.670 \mathrm{a}$ & -4.28 \\
\hline & Q4039 & $4 x$ & $0.670 \mathrm{a}$ & -4.28 \\
\hline \multirow[t]{2}{*}{ P. dedeccae } & V11796 & $2 \mathrm{x}$ & $0.750 \mathrm{a}$ & \\
\hline & Q3807 & $4 \mathrm{x}$ & $0.750 \mathrm{a}$ & 0 \\
\hline \multirow[t]{2}{*}{ P. lenticulare } & N188 & $2 \mathrm{x}$ & $0.750 \mathrm{a}$ & \\
\hline & $\begin{array}{l}\text { TK2417 } \\
\text { U54 }\end{array}$ & $\begin{array}{l}4 x \\
6 x\end{array}$ & $\begin{array}{l}0.750 \mathrm{a} \\
0.750 \mathrm{a}\end{array}$ & $\begin{array}{l}0 \\
0\end{array}$ \\
\hline \multirow{2}{*}{$\begin{array}{l}\text { P. malacophyl- } \\
\text { lum }\end{array}$} & V14855 & $2 \mathrm{x}$ & $1.000 \mathrm{~b}$ & \\
\hline & TK2449 & $4 \mathrm{x}$ & $0.850 \mathrm{a}$ & -15.00 \\
\hline \multirow[t]{5}{*}{ P. notatum } & Q4084 & $2 \mathrm{x}$ & $0.600 \mathrm{~b}$ & \\
\hline & $C 4-2 x$ & $2 \mathrm{x}$ & $0.600 \mathrm{~b}$ & \\
\hline & $C 4-4 x$ & $4 x$ & $0.600 \mathrm{~b}$ & 0 \\
\hline & Q4117 & $4 x$ & $0.550 \mathrm{a}$ & -8.30 \\
\hline & Q4188 & $4 x$ & $0.520 \mathrm{a}$ & -13.00 \\
\hline \multirow[t]{2}{*}{ P. plicatulum } & AH14 & $2 \mathrm{x}$ & $1.000 \mathrm{~b}$ & \\
\hline & Hoj388 & $4 \mathrm{x}$ & $0.710 \mathrm{a}$ & -29.00 \\
\hline \multirow[t]{2}{*}{ P. rufum } & Q3754 & $2 \mathrm{x}$ & $0.750 \mathrm{a}$ & \\
\hline & Q3785 & $4 x$ & $0.750 \mathrm{a}$ & 0 \\
\hline \multirow[t]{4}{*}{ P. simplex } & Q4109 & $2 \mathrm{x}$ & $0.750 \mathrm{a}$ & \\
\hline & U36 & $3 x$ & $0.840 \mathrm{ab}$ & +12.00 \\
\hline & U45 & $3 x$ & $0.870 \mathrm{~b}$ & +16.00 \\
\hline & Q4126 & $4 x$ & $0.750 \mathrm{a}$ & 0 \\
\hline \multirow[t]{3}{*}{ P. unispicatum } & U15 & $2 x$ & $0.570 \mathrm{a}$ & \\
\hline & Q4211 & $3 x$ & $0.570 \mathrm{a}$ & 0 \\
\hline & Q4265 & $4 x$ & $0.580 \mathrm{a}$ & +1.70 \\
\hline
\end{tabular}

Means followed by the same letter are not significantly different. Tukey test $(P=0.05)$

\section{Discussion}

We are recording the genome size of 47 species of Paspalum from which 29 are new records. The remaining 18 species have been recorded before (Bennett and Leitch 2010; Jarret et al. 1995). The DNA contents of a large list of 35 species of Paspalum published by Jarret et al. (1995) could be comparable with our results, because in both studies the DNA contents were measured with DAPI. Although the chromosome numbers are not indicated in Jarret's and co-workers list, now it would be possible to extrapolate 
their ploidies, providing that aneuploidy is not a common feature among Paspalum species. However, the range of variation in DNA content values that they have observed among accessions of the same species makes it difficult to ascertain what was the real ploidy level of some accessions. The information regarding the chromosome numbers of the analysed plants is crucial because in the genus Paspalum, multiploid species are the rule, i.e. species with different ploidy levels or in other words different cytotypes for the same species (Ortiz et al. 2013). The results indicated that P. almum, the species with a rare base chromosome number of $\mathrm{x}=6$, has a mean DNA content per chromosome higher than in any other species with $\mathrm{x}=10$.

Vaio et al. (2007) published another list of DNA contents for Paspalum species. Most of these species were allopolyploid and belong to the Dilatata group, while some putative diploid ancestors were also analysed. The DNA content was estimated by using flow cytometry and propidium iodide (PI) as fluorochrome, and the chromosome number for each species was informed. Some of the species of our list are coincident with the list of Vaio et al. (2007). In general, we observed somewhat lower $2 \mathrm{C}$-values for the same species. This may be due to the different stain reactions of the fluorochromes: PI binds base pairs of doublestranded DNA with very little or no base specificity while DAPI binds DNA preferentially to A-T base regions (Johnston et al., 1999). However, the scores that we obtained with DAPI should not be very far from the real values in picograms. In fact, our determination with DAPI of the biotype Virasoro of $P$. dilatatum was $2 \mathrm{C}=2.10 \mathrm{pg}$, while Vaio et al. (2007) reported a $2 \mathrm{C}$-value $9 \%$ higher $(2.29 \mathrm{pg})$ for the same plant material, i.e. accessions of a sexual autogamous species collected in the same wild population; or in a similar way, we observed $3.4 \mathrm{pg}$ in the apomictic hexaploid Uruguaiana biotype of $P$. dilatatum while Vaio et al. (2007) measured $3.69 \mathrm{pg}$ (8.5\% higher) for plant material collected in the same wild population.

We are reporting for the first time the reproductive mode of 12 species and one botanical variety. In addition, new information on reproductive mode is provided for 10 species concerning cytotypes that are different from the previous reported cytotype. The FCSS proved to be a reliable and very simple method to determine the reproductive mode in species of the genus Paspalum. We observed histograms with $2 \mathrm{C}+(3 \mathrm{C})$ peaks for all those species and cytotypes that have been reported to reproduce by sexual means. Likewise, histograms with $2 \mathrm{C}+(5 \mathrm{C})$ or other peak constitution characteristic of apomictic development were observed for all species or cytotypes that have been reported to be apomictic. Nonetheless, quantitative differences were found in reproductive mode of some species, as for example $P$. nicorae, a species considered earlier an obligate apomict according to cytoembryological studies
(Burson and Bennett 1970a). In fact, we confirmed the recent observation of Sartor et al. (2011) that most seeds of $P$. nicorae showed the $2 \mathrm{C}+(5 \mathrm{C})$ peaks characteristic of apomictic development, but a small proportion exhibited the $2 \mathrm{C}+(3 \mathrm{C})$ peaks indicating presence of sexual reproduction. Therefore, the species was considered to be facultative apomictic because it reproduced mainly by parthenogenesis and pseudogamy with some residual potentiality for sexual reproduction.

We observed exclusive $2 \mathrm{C}+(3 \mathrm{C})$ peaks in all sampled diploid species. However, previous embryological studies have demonstrated that the diploid cytotypes of several multiploid species usually developed not only a meiotic (cytologically reduced) embryo sac per ovule, but also an aposporous embryo sac (Caponio and Quarin 1993; Delgado et al. 2014; Hojsgaard et al. 2008; Norrmann et al. 1989; Quarin et al. 1982). The absence of seeds with 2C:5C embryo:endosperm ratio in diploid cytotypes was expected in our study because seeds came from open pollination. These diploids of multiploid species are highly outbreeders due to a self-incompatibility system (Quarin 1992). The functioning of the occasional aposporous embryo sacs was demonstrated when selfing was induced by mixed loads of self and heterospecific pollen (mentor effect) or by selfpollen combined with pollen of conspecific tetraploids; however, when pollination involved another genotype of the same diploid species, the progeny was formed exclusively by sexuality (Siena et al. 2008). In consequence, seeds bearing $2 \mathrm{C}: 3 \mathrm{C}$ embryo: endosperm ratios were primarily expected in our FCSS analysis of diploids because seeds had originated from open pollination.

Our data indicate that no correlation exist between the genome size and the reproduction mode of Paspalum material evaluated here. The results show a different scenario for coevolution of genome size and the reproduction mode than the situation pictured by Matzk et al. (2003) in the genus Hypericum (Clusiaceae). Several apomictic species have been identified in this genus, and with the exception of $H$. scabrum, all of them are facultative and pseudogamous apomicts that produce reduced male gametes, while H. scabrum is an obligate pseudogamous apomict, which produces unreduced male gametes. All facultative apomicts belong to two different sections of the genus: the phylogenetically younger section Hypericum and the evolutionarily older section Ascyreia. Within the section Hypericum the genome sizes of apomictic species are about twice those of the sexual ones, but the DNA increase is due exclusively to polyploidy because the $1 \mathrm{Cx}$-values of sexuals do not differ significantly from the DNA values of apomictic ones. However, in the section Ascyreia the apomictic species have significantly higher $1 \mathrm{Cx}$-values than the sexual species of the section and altogether, $85 \%$ of the total variation of the relative DNA content of the genus is found within 
this section. In a contrasting way, apomixis was found to occur in nearly all the infrageneric sections of the genus Paspalum analysed here, but there is not a direct correlation between the reproductive system and the variation of the $1 \mathrm{CX}$-value. Since important ranges of variation in $1 \mathrm{Cx}-$ value were observed among sexual as well as among apomictic entities, though the means were not significantly different between both categories, the evolutionary history of the reproductive mode in Paspalum may not be considered a parameter affecting the genome size in the genus.

Only four well represented categories were considered to analyse the relationship between the genome size and taxonomic grouping: the subgenus Anachyris and the groups Notata, Dilatata, and Plicatula of the subgenus Paspalum. The highest $1 \mathrm{Cx}$-values were observed in species of subgenus Anachyris and those of the Plicatula group, which are native to tropical regions of America though some of them are also distributed in the subtropics. In contrast, the lowest $1 \mathrm{Cx}$-values were observed in the analysed species of the Dilatata and the Notata groups, which are remarkably abundant throughout the humid subtropical and temperate regions of South America in southern Brazil, Uruguay and central and northeast of Argentina toward the Paraná River Delta and even further southeast in the Buenos Aires province. Notwithstanding, some species have been introduced and naturalized over many regions in the world including $P$. dilatatum, P. urvillei and P. notatum.

In general, we observed that the basic genome of Paspalum multiploid species was equal in size or very similar in different cytotypes of the same species. These results do not follow the general tendency observed by Leitch and Bennett (2004) concerning more than 3,000 species of angiosperms, which postulate that genome downsizing is a frequent phenomenon in polyploid angiosperms. Moreover, an opposite behaviour to this general tendency was observed in triploids of $P$. simplex, with a relative high value of mean basic genome size. Leitch and Bennett (2004) excluded all species with odd-ploids from their analysis, because data was available only for a few species. The odd-ploidy phenomenon and specially triploidy, though infrequent among most angiosperms, may play an important role as a bridge in the polyploidization processes and evolution of genera in which apomixes and autoploidy are so frequent like in Paspalum (Quarin 1992; Yamauchi et al. 2004). Considering this situation, we understand that the relation between triploidy and genome size deserves further research especially in multiploid species of Paspalum.

Finally, we had a very special opportunity to analyse the basic genome size in relation to polyploidization. The $\mathrm{C} 4-2 \mathrm{x}$ and C4-4x accessions of $P$. notatum are the diploid and the tetraploid plants, both obtained from a callus originated by tissue culture of a piece of young inflorescence, followed by colchicine treatment (Quarin et al. 2001). We observed the same $1 \mathrm{Cx}$-value for the induced autotetraploid plant $\mathrm{C} 4-4 \mathrm{x}$ than for the diploid C4-2x plant. The results support the suggestion that polyploid cytotypes in multiploid species arose from diploids through autopolyploidization (Quarin 1992). Our analyses indicated that in most multiploid species the diploid and the polyploidy co-specific counterparts have the same or not significantly different $1 \mathrm{CX}$-values. However, there are some exceptions in which the tetraploids cytotypes had much lower $1 \mathrm{Cx}$-values than their diploid counterparts, e.g. P. notatum, a species bearing different morphological biotypes at the tetraploid level. In this case, though the tetraploid cytotype likely originated by autoploidy, the tetraploid biotypes with lower 1Cx-value (taxonomically identified as co-specific variants) might have evolved through segmental allopolyploidy due to occasional hybridization with related species that have lower basic genome size. Interestingly, Dahmer et al. (2008) analysed the meiotic chromosome associations in 34 different accessions of tetraploid $P$. notatum; most of them showed a variable number of quadrivalent associations (suggesting autoploid origin), but some accessions showed exclusively 20 bivalent or with a very rare quadrivalent at first metaphase, a meiotic chromosome behaviour characteristic of alloploids or segmental allopolyploids. In fact, we observed the lowest $1 \mathrm{Cx}$-value in a particular sexual tetraploid genotype (Q4188) of this species obtained experimentally through chromosome doubling of a diploid, hybridization with different wild biotypes, and cycles of open pollination and selection.

Besides the special case of $P$. notatum, we observed important decreases of DNA contents in only two tetraploids with respect to their currently intraspecific diploid counterparts: P. malacophyllum $(-13 \%)$ and P. plicatulum $(-29 \%)$. However, this can be attributed to a taxonomic issue as a result of doubtful identification. In fact, in a recent study of genetic diversity in subgenus Anachyris concerning microsatellite markers and morphological characteristics, it was suggested that diploid accession V14855 of P. malacophyllum might belong to a new different species, while the tetraploid accession TK2449 fell into the clade of $P$. malacophyllum (Zilli et al. 2014). In the same way, both the diploid AH14 and the tetraploid Hoj388 accessions were doubtfully joined under the name of $P$. plicatulum. The doubt arose because Hoj388 have scaly rhizomes larger than usual for the species, though the general morphological characteristics resembled $P$. plicatulum. In both species the differences in morphological characteristics and in DNA content between diploid and tetraploid cytotypes may suggest that the tetraploid plants had not originated exclusively by autoploidy, but also by some occasional interspecific hybridization event.

Considering that the expected mean basic genome size should be the same for different cytotypes of multiploid species (based on the assumption that polyploid cytotypes arose by autoploidy), most polyploids showed either 
the expected genome size, in some cases a slight genome downsizing effect, or a slight increase in the size of the genome. Whether such genome size increases or decreases can be attributable to taxonomic issues like incorrect identification it remains to be supported.

Acknowledgments We thank to Fritz Matzk and Timothy Sharbel for collaboration and assistance, IPK Gatersleben, Deutschland. Dr. Henry A. Fribourg, Professor Emeritus of Crop Ecology, University of Tennessee, USA, for his kind review of the manuscript for English style and grammar. This work was supported by Facultad de Ciencias Agrarias Universidad Nacional del Nordeste, Corrientes, Argentina, grant PI-A008-2013; Consejo Nacional de Investigaciones Científicas y Técnicas (CONICET), Argentina, grant PIP-11220080101378; Agencia Nacional de Promoción Científica y Tecnológica (ANPCYT), Argentina, grant PICT2011-1802.

\section{References}

Albach DC, Greilhuber J (2004) Genome size variation and evolution in Veronica. Ann Bot 94:897-911

Bashaw EC, Holt EC (1958) Megasporogenesis, embryo sac development and embryogenesis in Dallisgrass, Paspalum dilatatum Poir. Agron J 50:753-756

Bashaw EC, Hovin AW, Holt EC (1970) Apomixis, its evolutionary significance and utilization in plant breeding. In: Norman MJT (eds) Proceeding 11th International Grassland Congress. Surfers Paradise, Queensland. University of Queensland Press, St. Lucia, pp 245-248

Bennett MD, Leitch IJ (2010) Plant DNA C-values Database (release 5-0, December 2010). http://data.kew.org/cvalues

Bennetzen JL, Kellog EA (1997) Do plants have a one-way ticket to genomic obesity? Plant Cell 9:1509-1514

Blount AR, Acuña CA (2009) Bahiagrass. In: Singh RJ (ed) Genetic resources, chromosome engineering, and crop improvement, vol 5. CRC, Boca Raton, pp 81-101

Bonilla JR, Quarin CL (1997) Diplosporous and aposporous apomixis in a pentaploid race of Paspalum minus. Plant Sci 127:97-104

Brown WV, Emery WHP (1958) Apomixis in the Gramineae: Panicoideae. Amer J Bot 45:253-263

Burson BL (1975) Cytology of some apomictic Paspalum species. Crop Sci 15:229-232

Burson BL (1985) Cytology of Paspalum chacoense and P. durifolium and their relationship to P. dilatatum. Bot Gaz 146:124-129

Burson BL (1997) Apomixis and sexuality in some Paspalum species. Crop Sci 37:1347-1351

Burson BL, Bennett HW (1970a) Cytology, method of reproduction, and fertility of Brunswickgrass, Paspalum nicorae Parodi. Crop Sci 10:184-187

Burson BL, Bennett HW (1970b) Cytology and reproduction of three Paspalum species. J Hered 61:129-132

Burson BL, Bennett HW (1971a) Chromosome numbers, microsporogenesis, and mode of reproduction of seven Paspalum species. Crop Sci 11:292-294

Burson BL, Bennett HW (1971b) Meiotic and reproductive behavior of some introduced Paspalum species. J Missis Acad Sci 17:5-8

Burson BL, Hussey MA (1998) Cytology of Paspalum malacophyllum and its relationship to $P$. juergensii and $P$. dilatatum. Int $\mathbf{J}$ Plant Sci 159:153-159

Burson BL, Quarin CL (1982) Cytology of Paspalum virgatum and its relationship with P.intermedium and P.jurgensii. Canad J Genet Cytol 24:219-226
Burson BL, Voigt PW, Evers GW (1991) Cytology, reproductive behavior, and forage potential of hexaploid dallisgrass biotypes. Crop Sci 31:636-641

Burton GW (1948) The method of reproduction in common Bahia grass, Paspalum notatum. J Amer Soc Agron 40:443-452

Burton GW (1967) A search for the origin of Pensacola bahia grass. Econ Bot 21:379-382

Burton GW, Forbes Jackson J (1970) Effect of ploidy on fertility and heterosis in Pensacola bahiagrass. Crop Sci 10:63-66

Caponio I, Quarin CL (1987) El sistema genético de Paspalum simplex y de un híbrido interespecífico con $P$. dilatatum. Kurtziana 19:35-45

Caponio I, Quarin CL (1993) Cytology and reproduction of Paspalum densum and its genomic relationship with $P$. intermedium and $P$. urvillei. J Hered 84:220-222

Chase A (1929) The North American species of Paspalum. Contrib US Natl Herb 28:1-310

Chase A (1939) Paspalum of South America. Hitchcock and Chase Library, Botany Department, Smithsonian Institution, Washington, D.C. Unpublished manuscript

Chrtek J Jr, Zahradníček J, Krak K, Fehrer J (2009) Genome size in Hieracium subgenus Hieracium (Asteraceae) is strongly correlated with major phylogenetic groups. Ann Bot 104:161-178

Dahmer N, Schifino-Wittmann MT, Dall'Agnol M, de Castro B (2008) Cytogenetic data for Paspalum notatum Flügge accessions. Sci Agric 65:381-388

Daurelio LD, Espinoza F, Quarin CL, Pessino SC (2004) Genetic diversity in sexual diploid and apomictic tetraploid populations of Paspalum notatum situated in sympatry or allopatry. Plant Syst Evol 244:189-199

Delgado L, Galdeano F, Sartor ME, Quarin CL, Ortiz JPA (2014) Analysis of variation for apomictic reproduction in diploid Paspalum rufum. Ann Bot 113:1211-1218

Di Rienzo JA, Casanoves F, Balzarini MG, Gonzalez L, Tablada M, Robledo C, W InfoStat versión (2014) Grupo InfoStat, FCA, Universidad Nacional de Córdoba, Argentina. http://www.infostat.com.ar

Enke N, Fuchs J, Gemeinholzer B (2011) Shrinking genomes? Evidence from genome size variation in Crepis (Compositae). Plant Biol 13:185-193

Espinoza F, Quarin CL (1997) Cytoembyology of Paspalum chaseanum and sexual diploid biotypes of two apomictic Paspalum species. Aust J Bot 45:871-877

Espinoza F, Urbani MH, Martínez EJ, Quarin CL (2001) The breeding system of three Paspalum species with forage potential. Trop Grass 35:211-217

Evers GW, Burson BL (2004) Dallisgrass and other Paspalum species. In: Moser LE, Burson BL, Sollenberger LE (eds) Warm season (C4) grasses. Agron Monogr 45. ASA, CSSA, SSSA, Madison, WI, pp 681-713

Forbes I, Burton GW (1961) Induction of tetraploidy and a rapid field method of detecting induced tetraploidy in Pensacola bahiagrass. Crop Sci 1:383

Greilhuber J, Doležel J, Lysa MA, Bennett MD (2005) The origin, evolution and proposed stabilization of the terms 'genome size' and C-value to describe nuclear DNA contents. Ann Bot 95:255-260

Hayman DL (1956) Cytological evidence of apomixis in Australian Paspalum dilatatum. J Aust Inst Agric Sci 22:292-293

Hojsgaard D, Shegg E, Valls JFM, Martinez EJ, Quarin CL (2008) Sexuality, apomixis, ploidy levels, and genomic relationships among four Paspalum species of the subgenus Anachyris (Poaceae). Flora 203:535-547

Jarret RL, Ozias-Akins P, Phatak S, Nadimpalli R, Duncan R, Hiliard S (1995) DNA contents in Paspalum spp. determined by flow cytometry. Gen Resour Crop Evol 42:237-242 
Johnston JS, Bennett MD, Rayburn AL, Galbraith DW, Price HJ (1999) Reference standars for determination of DNA content of plant nuclei. Am J Bot 86:609-613

Leitch IJ, Bennett MD (2004) Genome downsizing in polyploid plants. Biol J Linn Soc 82:651-663

Martínez EJ, Urbani MH, Quarin CL, Ortiz JP (2001) Inheritance of apospory in bahiagrass, Paspalum notatum. Hereditas 135:19-25

Matzk F, Meister A, Schubert I (2000) An efficient screen for reproductive pathways using mature seeds of monocots and dicots. Plant J 21:97-108

Matzk F, Meister A, Brutovská R, Schubert I (2001) Reconstruction of reproductive diversity in Hypericum perforatum L. opens novel strategies to manage apomixes. Plant J. 26:275-282

Matzk F, Hammer K, Schubert I (2003) Coevolution of apomixis and genome size within the genus Hypericum. Sex Plant Rep 16:51-58

Norrmann GA (1981) Citología y método de reproducción en dos especies de Paspalum (Graminieae). Bonplandia 5:149-158

Norrmann GA, Quarin CL, Burson BL (1989) Cytogenetics and reproductive behavior of different chromosome races in six Paspalum species. J Hered 80:24-28

Norrmann GA, Quarin CL, Killeen TJ (1994) Chromosome numbers in Bolivian grasses (Gramineae). Ann Mo Bot Gard 81:768-774

Novo PE, Espinoza F, Quarin CL (2013) An apomictic tetraploid Paspalum chaseanum cytotype and its cytogenetic relationship with $P$. plicatulum (Poaceae): taxonomic and genetic implications. Austr J Bot 61:538-543

Ortiz JPA, Quarin CL, Pessino SC, Acuña C, Martínez EJ, Espinoza F, Hojsgaard DH, Sartor ME, Cáceres ME, Pupilli F (2013) Hamessing apomictic reproduction in grasses what we have leamed from Paspalum. Ann Bot 112:767-787

Pritchard AJ (1970) Meiosis and embryo sac development in Urochloa mosambicensis and three Paspalum species. Austr J Agric Res 21:648-652

Pupilli F, Cáceres ME, Quarin CL, Arcioni S (1997) Segregation analysis of RFLP markers reveals a tetrasomic inheritance in apomictic Paspalum simplex. Genome 40:822-828

Quarin CL (1992) The nature of apomixis and its origin in Panicoid grasses. Apo News 5:8-15

Quarin CL (1994) A tetraploid cytotype of Paspalum durifolium: cytology, reproductive behavior and its relationship to diploid $P$. intermedium. Hereditas 121:115-118

Quarin CL, Burson BL (1991) Cytology of sexual and apomictic Paspalum species. Cytologia 56:223-228

Quarin CL, Caponio I (1995) Cytogenetics and reproduction of Paspalum dasypleurum and its hybrids with $P$. urvillei and $P$. dilatatum ssp. flavescens. Int J Plant Sci 156:232-235

Quarin CL, Hanna WW (1980a) Effect of three ploidy levels on meiosis and mode of reproduction in Paspalum hexastachyum. Crop Sci 20:69-75

Quarin CL, Hanna WW (1980b) Chromosome behavior, embryo sac development, and fertility of Paspalum modestum, P. boscianum, and $P$. conspersum. J Hered 71:419-422

Quarin CL, Norrmann GA (1987) Cytology and reproductive behavior of Paspalum equitans, P. ionanthum, and their hybrids with diploid and tetraploid cytotypes of $P$. cromyorrhizon. Bot Gaz 148:386-391
Quarin CL, Hanna WW, Fernández A (1982) Genetic studies in diploid and tetraploid Paspalum species. Embryo sac development, chromosome behavior, and fertility in $P$. cromyorrhizon, $P$. laxum, and P. proliferum. J Hered 73:254-256

Quarin CL, Burson BL, Burton GW (1984) Cytology of Intra and interspecific hybrids between two cytotypes of Paspalum notatum and $P$. cromyorrhizon. Bot Gaz 145:420-426

Quarin CL, Valls JFM, Urbani MH (1997) Cytological and reproductive behaviour of Paspalum atratum, a promising forage grass for the tropics. Trop Grassl 31:114-116

Quarin CL, Norrmann GA, Espinoza F (1998) Evidence for autopoliploidy in apomictic Paspalum rufum. Hereditas 129:119-124

Quarin CL, Espinoza F, Martinez EJ, Pessino SC, Bovo OA (2001) A rise of ploidy level induces the expression of apomixis in Paspalum notatum. Sex Plant Reprod 13:243-249

Rua GH, Speranza PR, Vaio M, Arakaki M (2010) A phylogenetic analysis of the genus Paspalum (Poaceae) based on cpDNA and morphology. Plant Syst Evol 288:227-243

Sartor ME, Quarin CL, Urbani MH, Espinoza F (2011) Ploidy levels and reproductive behavior in natural populations of five Paspalum species. Plant Syst Evol 293:31-41

Savidan Y (2007) Apomixis in higher plants. In: Hörandl E, Grossnicklaus U, Van Dijk PJ, Sharbel TF (eds) Apomixis: evolution, mechanisms and perspectives. ARG-Gantner, Ruggell, pp 15-22

Siena LA, Sartor ME, Espinoza F, Quarin CL, Ortiz JPA (2008) Genetic and embryological evidences of apomixis at the diploid level in Paspalum rufum support recurrent autopolyploidization in the species. Sex Plant Reprod 21:205-215

Smith BW (1948) Hybridity and apomixis in the perennial grass, Paspalum dilatatum. Genetics 33:628-629

Stein J, Quarin CL, Martínez EJ, Pessino SC, Ortiz JPA (2004) Tetraploid races of Paspalum notatum show polysomic inheritance and preferential chromosome pairing around the apospory-controling locus. Theor Appl Genet 109:186-191

Swift H (1950) The constancy of desoxyribose nucleic acid in plant nuclei. Proc Natl Acad Sci USA 36:643-654

Urbani MH, Quarin CL, Espinoza F, Penteado MIO, Rodrigues IF (2002) Cytogeography and reproduction of the Paspalum simplex polyploid complex. Plant Syst Evol 236:99-105

Vaio M, Mazzella C, Porro V, Speranza P, López-Carro B, Estramil E, Folle GA (2007) Nuclear DNA content in allopolyploid species and synthetic hybrids in the grass genus Paspalum. Plant Syst Evol 265:109-121

Yamauchi A, Hosokawa A, Nagata H, Shimoda M (2004) Triploid bridge and the role of parthenogenesis in the evolution of autoploidy. Am Nat 164:101-112

Zilli AL, Hojsgaard DH, Brugnoli EA, Acuña CA, Honfi AI, Urbani MH, Quarin CL, Martínez EJ (2014) Genetic relationship among Paspalum species of the subgenus Anachyris: Taxonomic and evolutionary implications. Flora. 209:604-612

Zuloaga FO, Morrone O (2005) Revisión de las especies de Paspalum para América del Sur Austral (Argentina, Bolivia, Sur de Brasil, Chile, Paraguay y Uruguay). Monogr Syst Bot Mo Bot Gar 102:1-297 